\title{
DETERMINATION OF POTENTIAL FLOODINGS THROUGH GEOINFORMATION TECHNOLOGY
}

\author{
Milen IVANOV \\ milen_i1970@abv.bg \\ Yavor YANKOV \\ yavorchoo@yahoo.com \\ “VASIL LEVSKI” NATIONAL MILITARY UNIVERSITY, VELIKO TARNOVO, BULGARIA
}

\begin{abstract}
The opportunity of researching and defining flooded areas using digital landscape model, hydrological analysis through specialized software and data processing in the GIS, is being unveiled. Multiple methods of defining flooded areas on the basis of result processing of transverse profiles of a specific area of the Rositsa River near the city of Sevlievo, are developed.
\end{abstract}

\section{KEYWORDS:}

River analysis system, geographic information systems, flooding, digital terrain model

\section{Introduction}

Natural and technological disaster and events monitoring is an important part of national security and sets the task of solving some basic problems like stabilization and surroundings improvement, liquidation and prevention of regional ecologic crises. This suggests developing a national system for monitoring, enabling operative solving of tasks connected with prevention and action during crises and consequences avoidance. Also, analyzing the stability of the functional structure of natural systems and making short-term prognosis.

\section{Characterization of Investigated Area}

The River valley of Yantra includes the River Yantra itself and it feeders, the bigger of which are the left ones: Rositsa River, Senovska, Eliiska, Studena reka and the right feeders: Dryanovska, Belitsa and Lefedja.

The more important feeders are: Rositsa River with length of $164.3 \mathrm{~km}$ and a catchment area of 2,261.9 $\mathrm{km}^{2}$, Lefedja River with $91.8 \mathrm{~km}$ length and catchment area of 
2,458.2 $\mathrm{km}^{2}$, Djulunitsa River with $85.3 \mathrm{~km}$ length and a catchment area of $864.3 \mathrm{~km}^{2}$, etc.

The area of catchment of Rositsa River is 2,262 $\mathrm{km}^{2}$ which represent $28.8 \%$ of Yantra River catchment area and its boundaries include:

- In the west and northwest - with the catchment area of Osam River;

- In the north, east and northeast with catchments of little rivers, which run directly into "Catchment of Rositsa River

- In thu suum vviu ur vaument area of Maritsa River.
Rositsa is a river with sizable seasonal fluctuations. The maximum flow is during April - May, due to thawing, and the minimal - during September. About $70-80 \%$ of the annual flow leaks out during the spring high water and in the summerautumn shallowness - about 9-10\%.

Rositsa River causes flooding very often and that's why almost along all the river the left bank is rectified with waterproof dikes. The river swells sometimes and causes flooding. The common physico-geographical characteristic is shown on Figure no. 1.

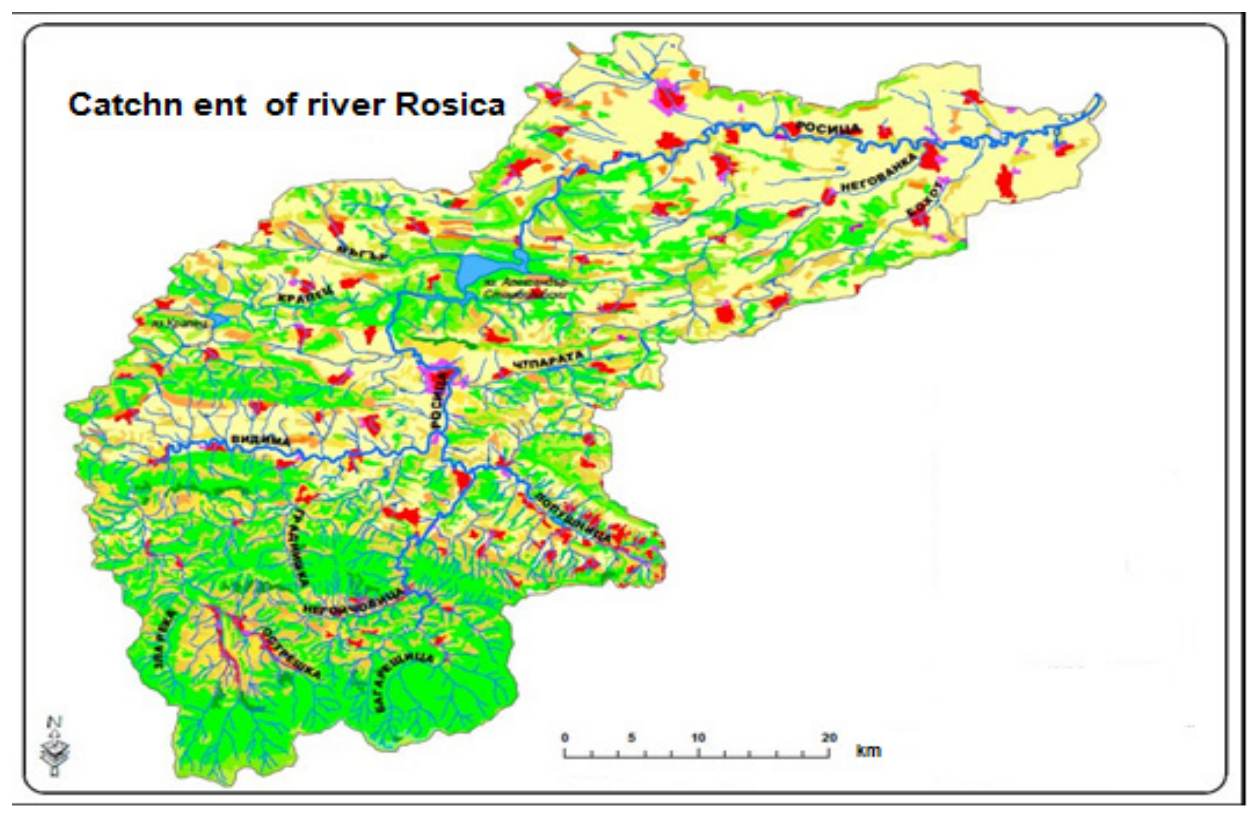

Figure no. 1 Common characteristic of Rositsa River

3. Creation of Digital Terrain Model

The digital terrain model (DTM) is discreet (through limited elements) and presents the surface relief. Coordinates $\mathrm{XYZ}$ of some points appear to be attributes of elements (primitives). The relief surface is described through elementary area elements, called facets. They can be generated from knots of regular or irregular set of points of model surface. Usually for analytic presentation of points from terrain surface a function, called prognosis (prediction), is used. Most often it is presented in description (1) and (2):

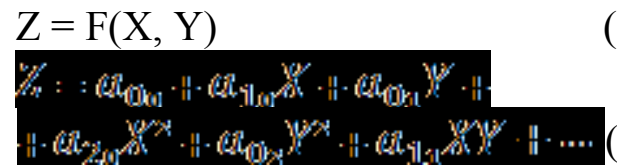

(1)

The extraction of information for topographic characteristics of a territory, which may be flooded at the respective water level, requires the presence of DTM. In (Keenan, 2006) the use of DTM from mission SRTM (Shuttle Radar Topography Mission) with space resolution $90 \mathrm{~m}$. is recommended. The usage of this model would be good for analysis at regional level, such as the generation of a catchment area and the extraction of its characteristics 
(slope, 3D area, etc.), but low space resolution makes it inapplicable for analysis at local level (for example determination of area and middle depth for floodplain areas in flooding).

This imposed the following sequence for using DTM sources:

- DTM made through LIDAR technique; 1:5.000;

- DTM generated from topo map $1: 25.000$.

\section{Flooding Assessment Procedure in the Danube Region}

The opportunities of present geoinformation technology allows the application of new methods in processing and interpreting different space information data. In this case the generation of different DTM excludes the subjective factor through structuring and analysis of results.

The structure of the geographic information system (GIS) is shown in appendix 1, allowing quantitative and space description needed for analysis of possible flooding from Rositsa River (Valchinov, 2003; Tepeliev et al, 2003). This approach allows optimizing risk assessment parameters.
Using GIS as an instrument for analysis and research of flooding for an exact territory can give higher-level accuracy results, concerning the impact on the environment.

\section{Characteristics of Methodology for} Analysis of Possible Flooding from Rositsa River

The methodology for analysis of possible flooding includes the following stages:

- DTM creation of relief model for Sevlievo territory, which can be used as a basis for putting necessary vector layers for flooding analysis;

- Setting vector layers necessary for flooding analysis;

- Formation of defined vector layers through satellite, land and GPS data in GIS;

- Design and realization of GIS on the basis of the created geo-information base and vector layers;

- Situation flooding analysis and its impact in a GIS environment.

Two different sources are used for generating DTM - the first based on spatial data and the second one on land data (Figure no. 2). The cell model size made from spatial data is $20 \mathrm{~m}$ and the second model $-10 \mathrm{~m}$.

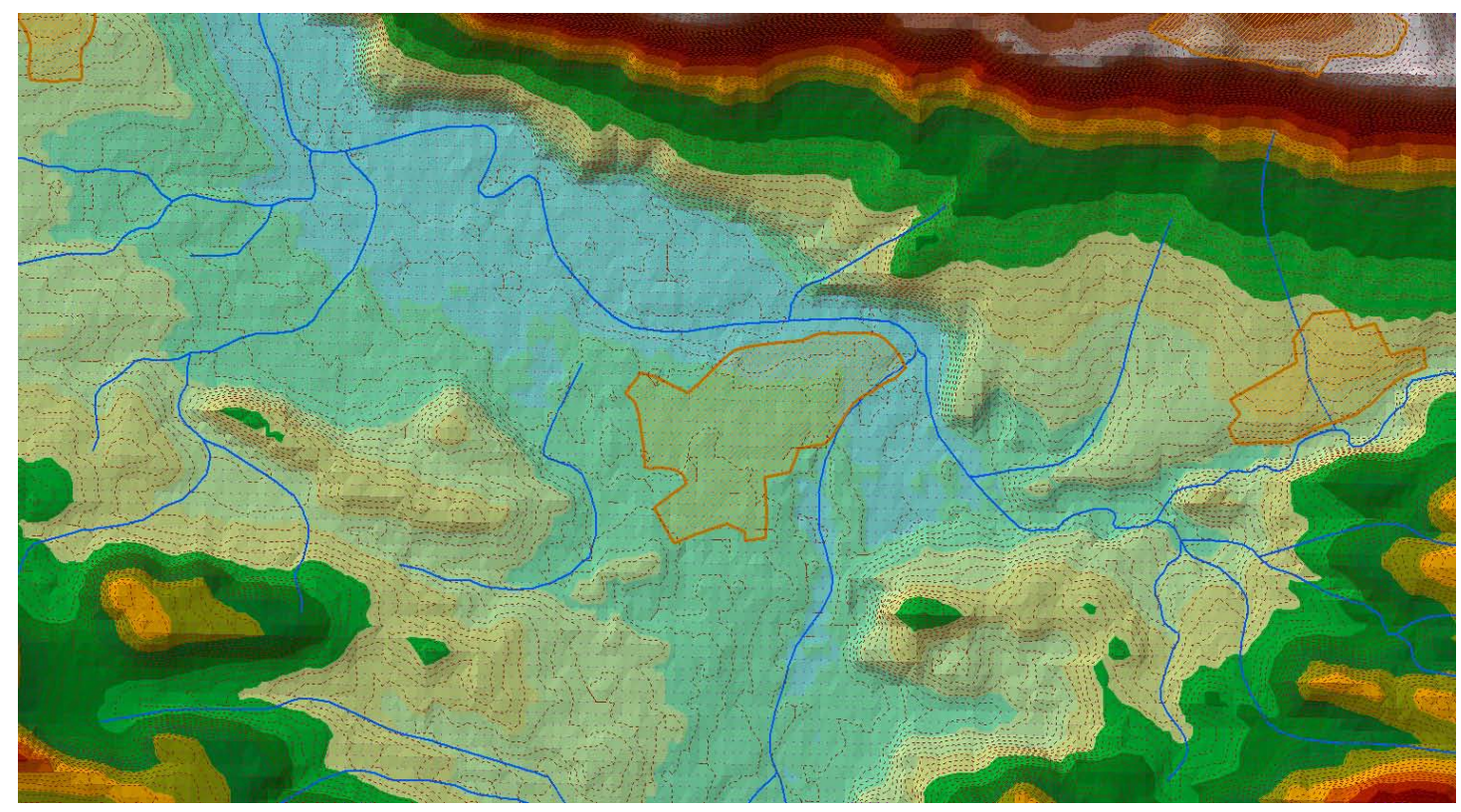

Figure no. 2 Land data for DTM 
The digital model with the smaller cell size, generated from larger-scale map technology, gives a detailed relief picture of the researched territory - Figure no. 3 .

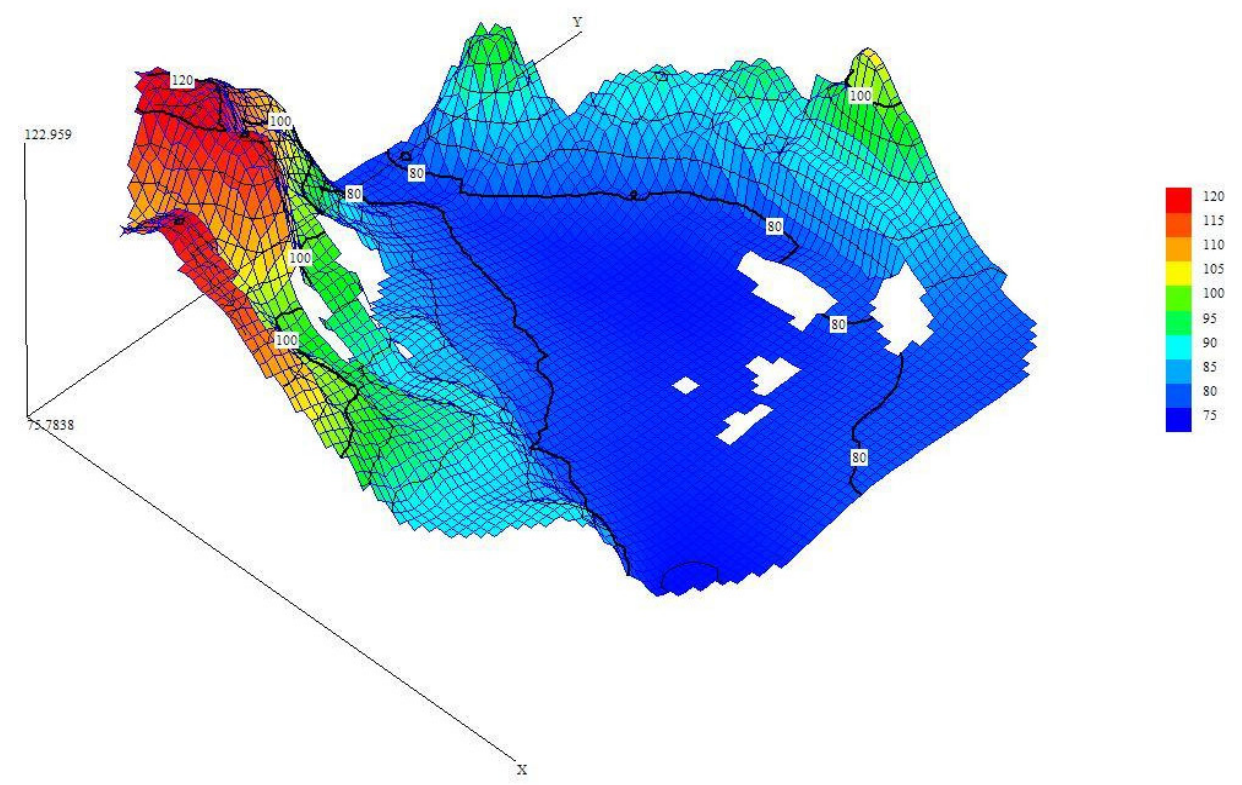

Figure no. 3 Relief model surface in the Sevlievo vicinity

6. Flooding Analysis in the GIS Environment on the Basis of the Suggested Methodology

A cross-section method is used to determine the average elevation above sea level for the adjacent territory of Sevlievo. Cross-sections are outlined in this method, approximately perpendicular of river stream - Figure no. 4.

Points with the same elevation above sea level are joined to the GIS environment. Thus, the flooding zones of Rositsa River are defined - Figure no. 5.

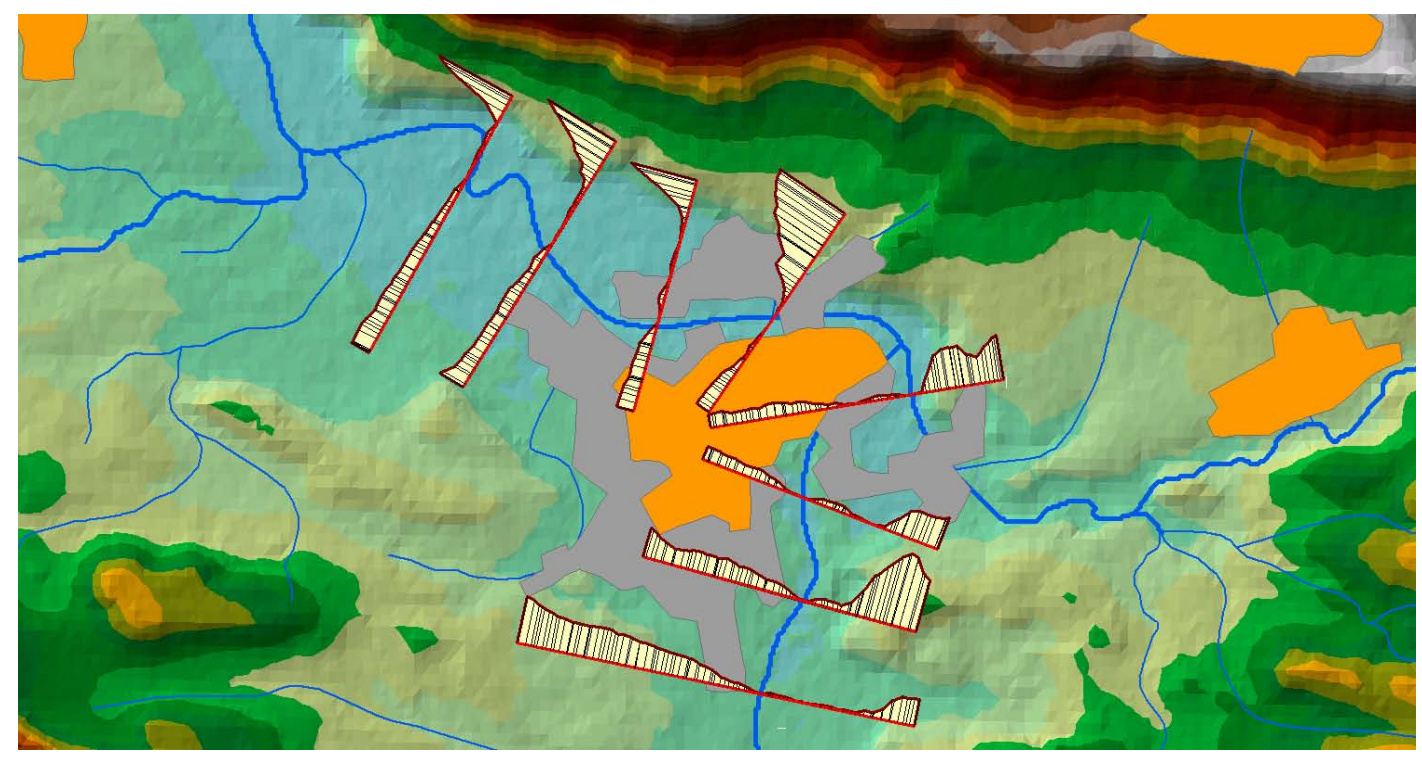

Figure no. 4 Cross-sections along Rositsa River 


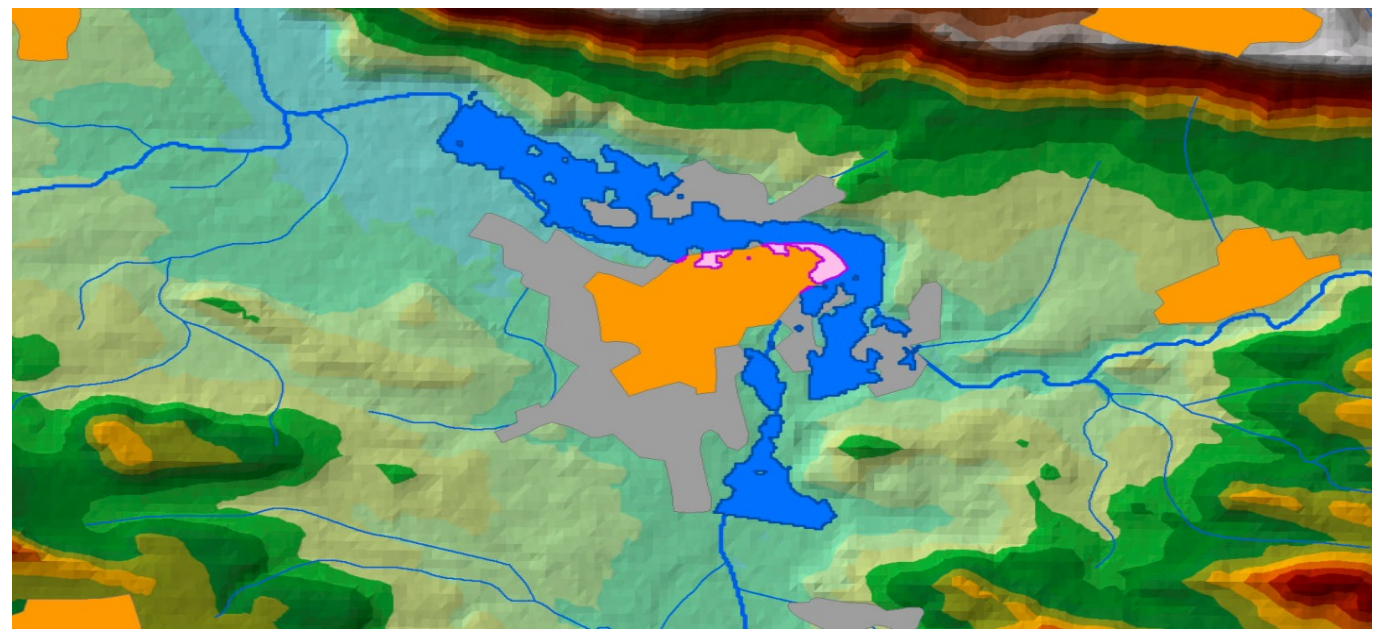

Figure no. 5 Flooding zones of Rositsa River near Sevlievo

\section{Conclusions}

GIS unifies traditional operation with database, like request and statistical analysis, with visualization advantages and spatial analysis, which maps offer.

These opportunities distinguish GIS from other information systems and give a unique opportunity for using them in a broad spectrum of tasks, connected with flooding analyses and prognoses of events and processes.
Data from GIS and satellite sensors play an important role in disaster management and crisis prevention. Their effective application depends not solely on technical specifications, but is influenced by factors such as data distribution, capacity building, institutional development and information sharing. While efforts are undertaken to develop new technologies in data collection and processing, the flow of data from providers to users has to be improved.

Appendix №1

GIS structure for flooding analysis

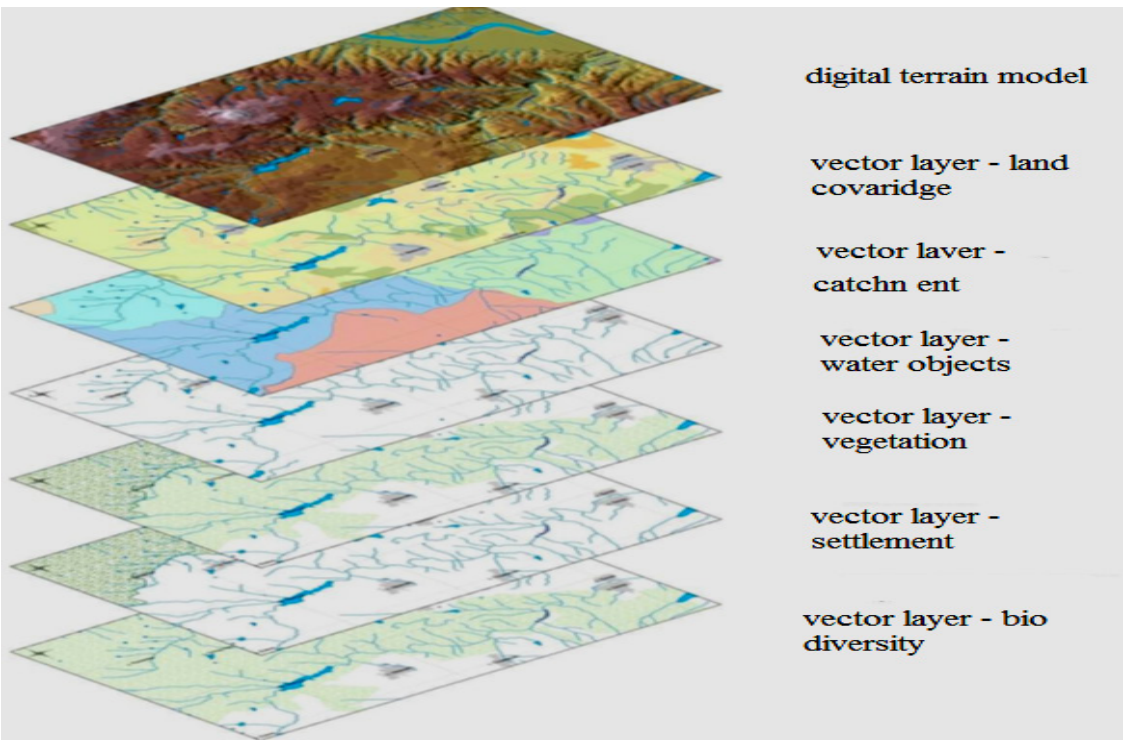




\section{REFERENCES}

Australian Government, Emergency Management Australia (EMA). Retrieved from: http://www.ema.gov.au/

Bahchevanov, G. et al. (2005). Crisis management operation. Sofia: MA Pres.

Buchanan-Smith, M. (2000). Role of Early Warning Systems in Decision Making Processes. Lisbon: Overseas Development Institute.

European Commission, (2007). Directive 2007/60/CE for estimation and management of flood risk. Strasburg.

Grasso, V. (2012). Early Warning Systems: State-of-Art Analysis and Future Directions. Nairobi: United Nations Environment Program.

Kamarashev, G. (2014). Crisis management. Veliko Tarnovo: NMU Pres.

Keenan, P.B. (2006). Spatial Decision Support Systems: A coming of age. Control and Cybernetics, vol. 35, No. 1 .

Manev, M. \& Ruseva, R. (2005). Crisis and conflict management. Sofia: MA Press

Mardirosan, G. (2007). Disasters and ecology collision. Sofia: AI "prof. Marin Drinov"

Murphy, L. (1995). Geographic Information Systems: Are They Decision Support Systems? Proceedings of the 28th Hawaii International Conference on System Sciences (HICSS '95), Hawaii.

Tepeliev, Y. et all. (2003). Geographic information system, Sofia: UASG

Valchinov, V. (2003). Geoinformatics, Sofia: UASG.

*** National program for disaster defense 2014-2018, Sofia.

*** Prevention law, vol.8, from 25 January, 2011.

*** Strategy for disaster risk reducing 2014-2020, Sofia. 